\title{
FISURAS EN LA PERCEPCIÓN DEL ENTORNO VISUAL URBANO
}

Gaps in the Perception of the Visual Urban Environment Raúl Yépez Collantes

ISSN (imp): 1390-4825

ISSN (e): 2477-9199

Fecha de recepción: 10/09/18

Fecha de aceptación: 05/22/19 


\section{Resumen:}

El presente artículo aborda el tema de la percepción del entorno urbano, por medio de la exploración y registro de ciertos elementos visuales efímeros que aparecen en la ciudad. Con el sustento de algunas consideraciones teóricas y con determinadas imágenes fotográficas de producción del autor, se patentiza la existencia de una ciudad paralela que convive con la que percibimos habitualmente. Apoyándose en las definiciones de morfología e iconografía urbana, se introduce en la comprensión de la estructura de la ciudad y, a través de los registros sensoriales y perceptivos, en como ella se convierte en una forma construida imaginariamente. El artículo enfatiza una instancia de vigencia de las ciudades que va más allá de lo puramente físico y formal, hasta el reconocimiento de lo intangible como elemento fenomenológico del paisaje urbano.

\section{Palabras clave:}

ciudad, entorno urbano, efímero, fotografía

\section{Abstract:}

This article deals with the topic of the perception of urban environment through the exploration and register of some temporary visual elements that appear in the city. With the support of theoretical considerations and photographic images of the author's production, it is obvious the existence of a parallel city that coexists with the one usually perceived. Based on the definitions of urban morphology and iconography, the author introduces the structure of cities through sensory and perceptual registers, and how it becomes an imaginatively constructed form. The article emphasizes in an instance of authenticity for cities that goes beyond, from the purely physical and formal, to the recognition of the intangible and phenomenological as elements in the urban landscape.

\section{Key Words:}

city, urban environment, ephemeral, photography

\section{Biografía del autor:}

Msc. Arq. Raúl Yépez Collantes [YEPO] (Ibarra, Ecuador 1968)Arquitecto por la Facultad de Arquitectura y Urbanismo de la Universidad Central del Ecuador, (FAU-UC), Quito-Ecuador. Máster en Cultura Visual. Becario del gobierno brasileño mediante proceso selectivo (primer lugar) del Programa de Postgrado de la Universidad Federal de Goiás, FAV-UFG, Goiás-Brasil, 2010. Área de Concentración en Procesos y Sistemas Visuales. Docente universitario, fotógrafo profesional y artista investigador en el campo del lenguaje fotográfico. Ganador de varios concursos de fotografía. Ha presentado diversas exposiciones de fotografía desde el año 1988, hasta la actualidad dentro y fuera del país; impartido charlas sobre su trabajo creativo y ha participado en varias publicaciones. 


\section{Introducción}

El presente artículo, su fundamentación teórica y las patentes visuales que se acompañan, fragmentos fotográficos del Centro Histórico de Quito, exploran el lenguaje de lo efímero en el paisaje urbano e intentan revelar una ciudad "oculta". Una urbe paralela que convive con nosotros aunque esté fluctuando en el mundo de lo impalpable. Así lo había esbozado e inclusive narrado con fuerza vivencial, en "Los secretos visibles de la ciudad", disertación presentada para la obtención del título de Master en Cultura Visual, por la UFG, Brasil, en el año 2010.

En la construcción ficticia de estas ciudades paralelas, ciertos lugares, aunque visibles todo el día, "aparecen" a los ojos voraces del investigador artista únicamente en brevísimos momentos. Cada componente del mobiliario urbano o detalle arquitectónico normalmente inadvertido por el habitante común se transforma en un potencial referente visual que adquiere vida propia, sale del anonimato y surge con elocuencia por la invasiva y pasajera incidencia de la luz sobre él en una exacta fracción de segundo. En ese caso, los elementos urbanos convertidos en "motivo" aparecen a la vista, hacen un llamado de alerta, emergen de un efecto provisorio y ultrapasan el filtro subjetivo/mediador del observador para ser capturados y concretizados en imagen. El resultado de ese proceso, ciertas fotografías del autor, se constituyen en la evidencia tangible de la presente exploración.

Dependiendo del grado de convivencia que tengamos con nuestro entorno construido, la percepción de la ciudad, con toda certeza, será más o menos disímil para cada persona. Si adicionalmente agregamos las condiciones atmosféricas, la hora del día, la posición del sol, la diversidad de los lugares con sus atributos cenestésicos, podemos advertir, sin lugar a equivocarnos, que no existen características únicas atribuibles a un determinado espacio urbano. Los elementos identificadores pasan por un patrón de coordenadas y nombres propios, mas difieren según el canon perceptivo y el punto de vista de cada concurrente. En todo caso, la ciudad es el contenedor de cada elemento protagónico encontrado y convertido en imagen.

\section{Teorizando el escenario}

La ciudad es el escenario de donde se extrae el producto gráfico de este trabajo. La ciudad compleja de prácticas y representaciones sociales organizadas e idealizadas bajo una multiplicidad de factores. Según Ulpiano T. Bezerra de Meneses (1996) se recomienda tener presente que la ciudad "debe ser entendida según tres dimensiones solidariamente imbricadas, cada una dependiendo profundamente de las demás, en relación simbiótica: la ciudad es artefacto, es campo de fuerzas y es imagen"(p. 148). Como artefacto la ciudad sería una estructura social compleja producida históricamente a la cual se confiere forma, función y sentido. Está regulada por un "campo de fuerzas" territoriales, políticas, económicas, culturales y especulativas en tensión constante $\mathrm{y}$, responde a un imaginario visual al que se incorporan, además de la pura imagen, otras categorías, como ideología, valores, memoria, etc., bajo el concepto de representación, que es lo que da cuenta de la complejidad de la imagen. De acuerdo con Meneses (1996), la imagen, por tanto, es una forma que sirve de soporte a las representaciones:

\begin{abstract}
No tendría, pues, sentido buscar en estas imágenes apenas registros de un supuesto real externo y objetivo y evaluar el grado de felicidad en la correspondencia de atributos. Al contrario, la imagen es una construcción discursiva, que depende de las formas históricas de percepción y lectura, de los lenguajes y técnicas disponibles, de los conceptos y valores vigentes (p.152).
\end{abstract}

Por otro lado, la ciudad también puede ser analizada desde el campo de la iconografía y para eso, conviene traer algunas consideraciones del artículo "La iconografía urbana y los espacios escénicos de la memoria de la ciudad", de Sandra Makowiecky, en el cual menciona teorías sobre el paisaje urbano contenidas en el libro The City of Collective Memory. Its Historical Imagery and Architectural Entertainments, de Christine Boyer (1994). 
Ella indica que, según Boyer, se distinguen tres "mapas" principales: la ciudad como obra de arte, característica de la ciudad tradicional; la ciudad como panorama, característica de la ciudad moderna; y la ciudad como espectáculo, característica de la ciudad contemporánea” (Makowiecky, 2007, p. 34).

Tratando de auscultar brevemente la visión de Boyer, encontramos que la ciudad tradicional, caracterizada como obra de arte, contemplaba una práctica en la cual la moldura de la pintura se tornaba emblemática.

La ciudad moderna, en cambio, caracterizada como panorama, abarca el período en que, según Boyer, la imagen pasa por la sociedad moderna a través de un mirar totalizante. En ese caso, la ciudad aparecía con un orden espacial abierto y expansivo, reglado por una transformación del espacio y tiempo engendrados por los medios de transporte modernos y regulados por cánones de eficiencia y funcionalidad. Sobre esta convención estética de la ciudad, Makowiecky (2007) afirma que, al contrario de los dictados de Le Corbusier, que preveían el espacio como foco de preocupación social y objeto de investigación y control,

En todos los lugares el arquitecto y el planificador urbano fragmentan el tejido en unidades discretas y las recomponen como en un todo estructurado utópico: desorden fue sustituido por orden funcional, diversidad por repetición en serie, y sorpresa por expectativa uniforme. Al descomponer la ciudad en sitios homogéneos, los lugares quedaron vacíos de referencia histórica $(2007$, p. 46).

Respecto a la ciudad contemporánea, caracterizada como espectáculo, Boyer la expone como la substitución del mundo material por bandas invisibles de comunicación electrónica circundando el globo, por ambientes visuales estimulados por computador; una ciudad concientizada. Esta ciudad del espectáculo crea imágenes manipuladas y arregladas para representar una estética, según Boyer, comprometida con la repetición de modelos ya conocidos y de conjuntos formales. Ya Makowiecky (2017) por su parte, encuentra al respecto, un elemento crítico cuando asegura que: "En esa mimética de algoritmos computacionales, lenguajes modelo generan parcelas fragmentadas del espacio de la ciudad como elementos autónomos que no dicen nada sobre la ciudad como un todo"(p.56). Pero va más allá, cuando expone que además de los cambios ocurridos en la estructura de la ciudad, con el tiempo, también cambian las formas representacionales:

Cada discurso establece un orden espacial, una imagen congelada que captura la manera en la cual el presente transitorio es percibido. Las formas representacionales se tornan registros sucintos de lo que nosotros consideramos ser la realidad presente. Esos modelos estéticos transforman nuestro sentido de lo real, pues la imagen de la ciudad es un concepto abstracto, una forma construida imaginariamente. (Makowiecky, 2007, p.35)

No importa si somos investigadores o simples moradores de la ciudad, el hecho es que ella nos pertenece y hace parte de nuestro imaginario y de nuestra identidad. En esta dinámica vale, la pena proponer, develar la existencia de ciudades paralelas, ciudades visuales, ciudades efímeras, que aunque surjan inadvertidas por momentos de corta duración, pueden ser perennizadas y materializadas a través de la fotografía.

\section{Imaginarios visuales}

De las definiciones anotadas sobre la morfología e iconografía urbanas habremos de extraer aquello relacionado con los imaginarios visuales, hilo conductor y elemento fundamental de nuestro estudio, dentro del cual, el ser humano es actor, transeúnte y espectador a la vez, de los submundos que habita. Para Makowiecky, (2007), "la imagen de la ciudad es un concepto abstracto, una forma construida imaginariamente" (p.35). La Ciudad Imagen de Meneses (1996), está entendida, como quedó dicho, desde un "imaginario visual al que se incorporan, además de la pura imagen, otras categorías, como ideología, valores, memoria, etc., bajo el concepto de representación - que es lo que da cuenta de la complejidad de la imagen" (p.152). Pero de un modo u otro, podría entenderse que los imaginarios trabajan sobre "lo visible". Así lo asegura Armando Silva en su libro Imaginarios, el asombro social ,en el capítulo que trata de los "imaginarios ciudadanos":

"El arte no reproduce lo visible, hace visibilidades", reseñó Paúl Klee, lo que puede ser la ruta de los estudios de los imaginarios en cuanto a que se trabaja 
sobre lo visible, sobre los iconos de la globalización y sus contactos mundiales en el sentido del presente capítulo, pero para "hacer ver" lo que se está viendo todos los días sin las suficientes conexiones de sentidos desplazados. Así que el artista y otros productores culturales no tienen ciertamente, el monopolio de la creatividad visual. También la poseen los ciudadanos en sus ejercicios colectivos de percepción y categorización del mundo. (Silva, 2014, p. 75).

Sea que las formas representacionales se conviertan en "registros sucintos" de la realidad, como menciona Makowiecky, o que los ciudadanos posean "ejercicios colectivos de percepción" como lo afirma Silva, al parecer, hay un escenario latente sobre el que se mueven un elenco de actores directos, (pobladores con sus "sentidos desplazados") llevando una carga de "ideología, valores y memoria”.

\section{Las fisuras}

Con estas presunciones en bandeja y teniendo presente la construcción de sentido de la imagen fotográfica y su complejidad desde el punto de vista de la representación, intento revelar la existencia de "otras" ciudades, a través de una visión desde el arte de la imagen y de lo visible. Ofrezco el reto de mostrar aquello que no haya sido registrado en el imaginario ciudadano, un conjunto de fisuras en la percepción del entorno visual urbano. Un descubrimiento atemporal con la imagen fija y una provocación que consiste en mostrar lo que está ahí cuando estamos sin estar, recorriendo una plaza o una calle. Quizá sea también un modo personal de hacer "visibilidades", convertir esos referentes fotográficos que existen por el azar, en las más claras evidencias de una realidad que no perdura, sino en la propia imagen capturada y publicada.

Bajo esta perspectiva, la primera fisura aparece rastreando el valor estético de lo cotidiano. Para explorar este enunciado, escogeré un par de imágenes que formaron parte de mi exposición El otro paisaje del año 2001, antecedo el decir al ver, porque hay un lenguaje escrito con palabras que induce al juego de probar el poder de las solas imágenes. Puede verse, entonces, en la primera fotografía, el resplandor del ocaso sobre unas tablas que cumplían la función de cerco emergente en un terreno cualquiera de la urbe. Al recorrer de cerca alrededor del límite externo del terreno apareció sobre la superficie de alguna de esas tablas, una anomalía que decidí fotografiar. El efecto llamaba mucho la atención, las tonalidades parduscas desde el amarillo hasta el ocre, junto con la sombra crearon un caprichoso contraste, una imagen que en su conjunto muestra figuras al gusto del lector; el hueco redondo recuerda un ojo y la sombra, una cabeza; algunos ya encontraron inclusive una máscara, la cara de un buey y así por delante. (Figura 1)

Sin embargo, lo que puede mirarse es una imagen abstracta, conformada por un conjunto de líneas y planos geométricos sobre los cuales irrumpen huecos y sombras, la sensación del caos, la superposición de fragmentos desordenados y pegados al azar. De alguna forma, una apología al crecimiento de las grandes ciudades, donde impera el descontrol.

La imagen está dividida en dos partes cortadas por un eje vertical invisible, casi en el propio centro del cuadro. El eje acaba siendo la profundidad misteriosa, lo desconocido, la incerteza de lo que existe oculto en el desenfoque. Curiosamente, en este caso, ese espacio del fondo atrás de la cerca, indefinido, desmaterializado, cobra importancia posiblemente debido al marco acuńado de la sombra. A partir de allí, el ojo recorre la totalidad de la fotografía observando tanto esta parte cuanto la otra, perfectamente nítida en sus contornos y extremos.

Cuando cercana, la mirada envuelve al observador en un universo figurativo del material vivo, específico, expresivo en la textura visual de suave rigurosidad y cuando lejana, este es mágicamente sumergido en el campo de la abstracción. La experiencia un tanto contraria a los normales preceptos de la doctrina, confirma precisamente la hipótesis de la percepción dinámica de la obra de arte fundada por el pensamiento romántico y las teorías psicológicas de la segunda mitad del siglo XIX: "los valores de la obra radicaban en la percepción visual o táctil, distante o cercana, estática o dinámica, frontal o cinemática, del espectador" (Montaner, 2002, p.66).

Buscando motivos que puedan transformar nuestras ideas en imagen, solemos dirigir la atención a un elemento específico, pero en el justo momento de escoger el objeto para hacerle una foto, por alguna causa indescifrable, es el objeto el que le escoge a uno. La conexión sucede en un acto repentino, como si una fuerza invisible condujese el ojo hacia la escena. Fue de este modo que un poste de luz cualquiera, de tantos miles 


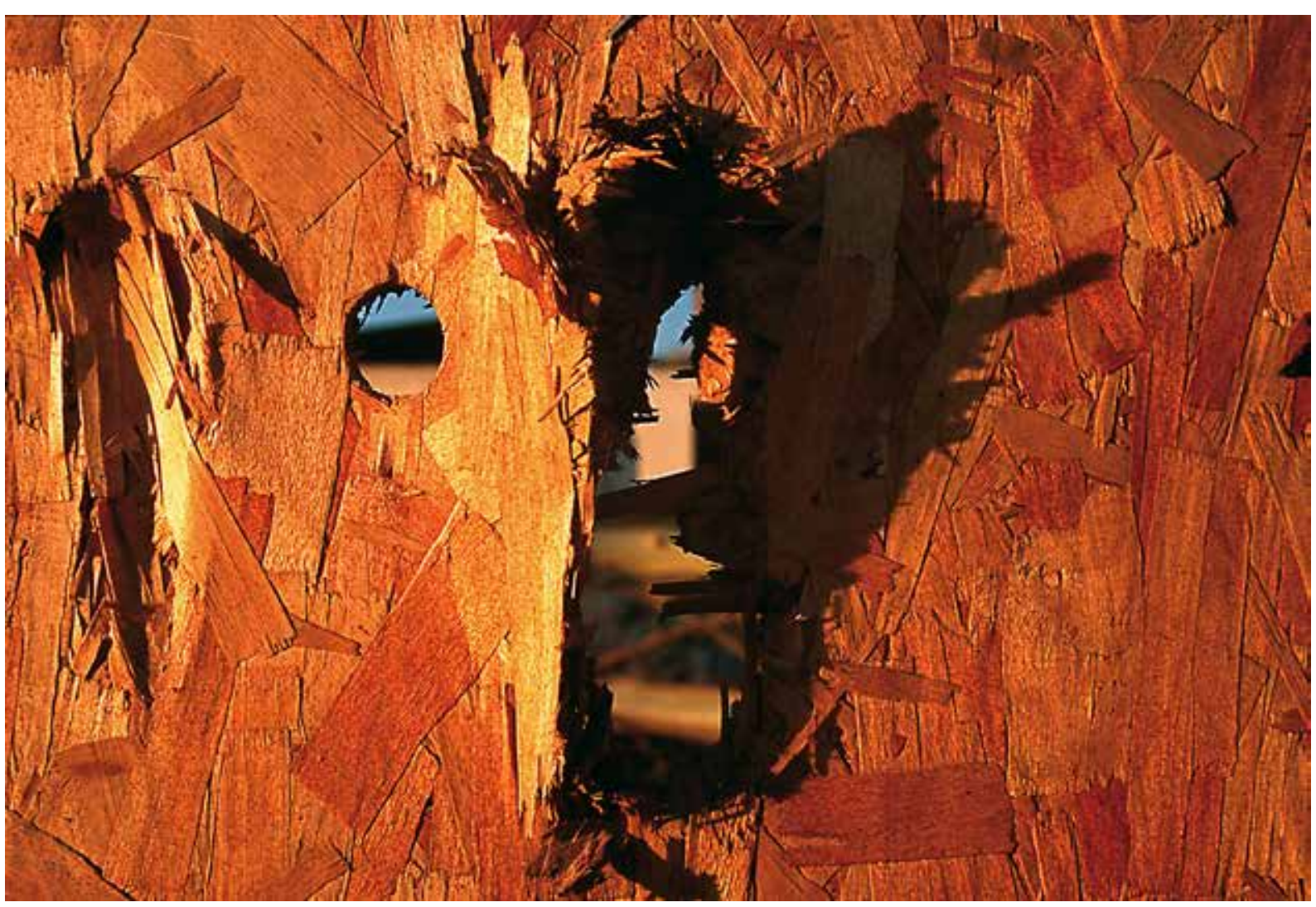

Figura 1. Raúl Yépez Collantes [YEPO]. Quito, mayo de 1999.

De la serie El otro paisaje. Fuente: www.yepo-photo.com

que están distribuidos por las calles, sea el motivo para la fotografía de la Figura 2.

Puede verse en primer plano, la presencia de un cable de acero fijado verticalmente por dos alambres de menor espesor, estos últimos permanecen en posición horizontal, originando una sombra dura. Por la figura que esa sombra describe alrededor de la superficie cilíndrica del poste, da para imaginar que los dos alambres que fijan el cable, están ligeramente alejados del poste, lo que introduce el efecto de tercera dimensión y profundidad a la imagen. El fondo colorido revela el resquicio de algún grafiti o propaganda política temporal en visible proceso de deterioro, actuando como una pantalla de rica trama y cálida sensación cromática debido a la gama de matices amarillos, naranjas y rojos. La marca del tiempo borró parcialmente las pinturas, dejando bordes accidentados, mezclas de colores e innúmeras porosidades de varios diámetros que imprimen dramáticas texturas.

La intersección de los alambres colocados en el tercio superior del encuadre, sumado a la sombra que producen, recuerda el símbolo de la cruz latina y si llegásemos a percibir lo que algunos, con gran imaginación encuentran, hasta veríamos la alegoría de un hombre crucificado como representación del hombre oprimido por la metrópoli. Lo que se obtuvo, finalmente a mi juicio fue una imagen enigmática. Si yo no explicase, nadie sabría lo que es, ya que difícilmente se percibe una analogía con su referente. Se espera que el matiz gris del cemento sea el vestigio más cercano al objeto real (poste), mas eso es relativo, el indicio carece de contundencia.

Por último se puede observar que la fotografía está dividida en tres fragmentos de la misma imagen, juntos, uno al lado del otro. Dividir la imagen permite, por un lado, la posibilidad de advertir detalles que no fueron vistos en la visión general de la unidad y, por otro, me daba la oportunidad de representar la fragmentación como una de las principales características de la sociedad urbana a finales del siglo XX.

La segunda fisura que sondearemos, surge de la intangibilidad de los reflejos. En este caso, se trata de aquellas apariciones que, tal como si fuesen en un espejo, se muestran sobre la superficie de pequeñas porciones de agua atrapadas en las concavidades de los diferentes pisos de la urbe. 

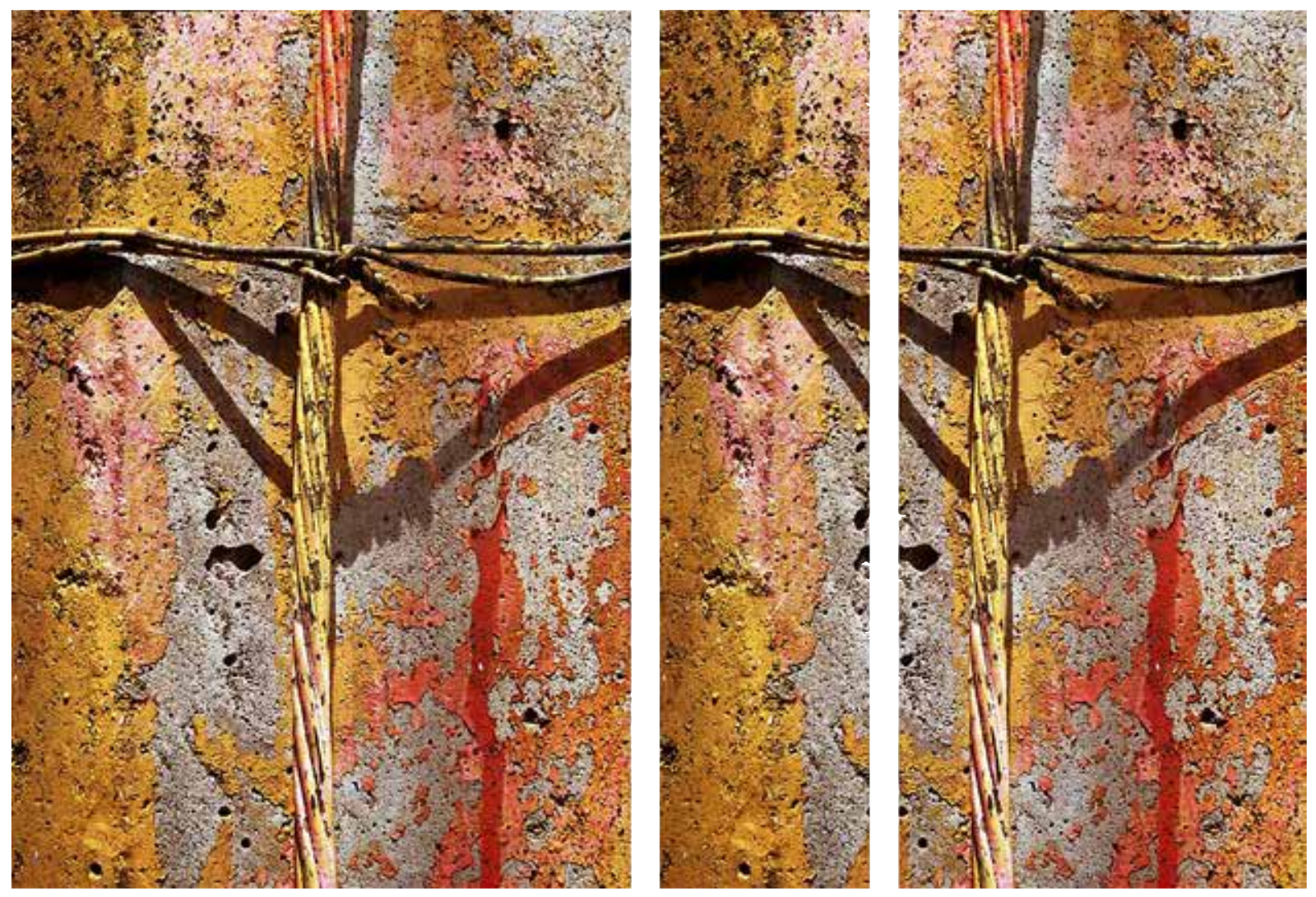

Figura 2. Raúl Yépez Collantes [YEPO]. Quito, mayo de 1999.

De la serie El otro paisaje. Fuente: www.yepo-photo.com

Para explicarlo con imágenes veremos un par de fotografías que fueron parte de La Memoria de los Charcos, muestra presentada en el año 2005. La primera tiene un valor especial por el carácter sorpresivo del hallazgo. Esperando que amanezca el día en la Plaza de la Independencia del Centro Histórico de Quito, vi como fueron apareciendo los fulgores de pequeñas porciones de agua que habían quedado estancadas en las depresiones del piso. Desde el lugar donde permanecía sentado podía verse un efecto conmovedor. Allí mismo, en perfecto ángulo de visión, surgió en frente de mis ojos uno de esos charcos de agua, revelándome el encanto de su reflejo especular.

En lo profundo del hoyo, vi cómo se reproducían con nitidez algunos detalles arquitectónicos de los edificios contiguos que integran el conjunto de monumentos alrededor de la plaza. Reconocí los aditamentos del estilo gótico que decoran la parte superior del pórtico principal de la iglesia La Catedral, llamado de Domo de Carondelet. La imagen lógicamente invertida, con todos sus elementos boca abajo, emergía reluciente del contraste entre el blanco de las mamposterías y el azul intenso del cielo.
Completé rápidamente algunas pruebas y determiné que resulta imperativo incluir dentro del encuadre una buena porción del área circundante debido a la importancia del efecto ser percibido en el contexto. Elegí, en consecuencia la opción vertical y coloqué los cuerpos reflejados en la parte inferior, pero moviendo el ángulo de modo que las líneas de unión del piso de piedra tallada atravesasen el cuadro en sentido oblicuo. Finalmente ajusté el enfoque en el reflejo con la intención de jerarquizar únicamente el efecto, dejando el resto sutilmente desenfocado. Hice de este modo mi primera foto de la serie de los charcos (Figura 3).

No había transcurrido mucho tiempo cuando noté que la luz del día se había apoderado de la totalidad de la plaza y más personas pululaban por todo el lugar. Siempre viendo para abajo, iba y volvía con la ilusión de captar más efectos del mismo estilo, pero en un instante todo cambio, asistí perplejo a un espectáculo perturbador: vi consternado cómo, con ansia devoradora, el sol tragaba los charcos a violentas bocanadas. En un parpadeo de ojos los hoyos de agua habían desaparecido definitivamente. Entendí por primera vez, que el efecto visual era absolutamente pasajero y que sus códigos hacían parte del 
lenguaje de lo efímero.

En términos concretos, el reflejo no es otra cosa que una construcción ficcional, un efecto gobernado por la luz que necesita ciertas condiciones para ser percibido. Desde el punto de vista físico, está relacionado con las propiedades de la propagación de la luz: cuando los rayos incidentes alcanzan una superficie totalmente lisa, ocurre una "reflexión especular"; por otro lado, si la superficie de incidencia es irregular, llena de imperfecciones, los rayos de luz no son bien reflejados y de esa forma, ocurre lo que se llama "reflexión difusa". En el caso de los charcos, la superficie de agua, cuando está calmada y no hay incidencia del viento que la vuelva voluble, resulta ser plana y pulida como un espejo, produciéndose la reflexión especular.

El reflejo en el piso es percibido en un campo visual restringido que depende del tamaño del charco, de la distancia del observador al charco y de la localización del charco en relación al observador. La horizontalidad del agua empozada provoca que el objeto reflejado pierda la relación de posición, tamaño y distancia, tanto así que lo que se mira, es una imagen invertida en el eje vertical, o sea, el monumento patrimonial (o lo que fuese), cabeza abajo. Posiblemente, aunque resulte casi obvio, esa sea la cualidad más notoria de esta propuesta. Otra característica interesante es que, si bien el charco como tal es real, en cambio la imagen reflejada sobre él es virtual. El agua del charco real y material, como siendo una superficie plana, muestra una imagen virtual e inmaterial, con volumen, formada por el proceso de prolongamiento de los rayos luminosos reflejados. Eso explica por qué todo reflejo virtual parece estar "en el interior" de la superficie y necesita de sombra para ser apreciado en toda su magnitud (Figura 4) .

Considerando el fenómeno psicológico fundamental llamado de "doble realidad perceptiva de las imágenes", sabemos que observando una imagen fotográfica "percibimos simultáneamente esa imagen como fragmento de superficie plana y como fragmento de espacio tridimensional" (Aumont, 1993, p.63). En otras palabras, al mismo tiempo en que teniendo la foto en nuestras manos, la distinguimos como un objeto físico, también nos sumergimos mentalmente en el contenido de la imagen, percibiendo su espacialidad y transportándonos al instante de una escena real. Ahora, es curioso observar una foto del reflejo en el charco, aquello que estaríamos imaginando como una escena real acaba siendo una imagen virtual, un efecto irreal e intangible.

Desde el punto de vista conceptual, el reflejo hace parte del discurso en torno de lo efímero y tiene en este estudio dos frentes específicos, uno de ellos está relacionado con la percepción de la imagen por el espectador, y la otra, con la propia presencia del efecto como siendo una fisura, un elemento que habita los mundos paralelos en el entorno urbano. Aparte de ser la fotografía el medio por el cual el autor visa establecer su relación con el mundo, el efecto en sí simboliza el encanto de lo fugaz, el misterio de lo ilusorio; como en la 'Tamara' de Calvino, (1990) "los ojos no ven cosas mas figuras de cosas que significan otras cosas" (p.17), una lección de lo transitorio de la vida, afianzándonos al presente. La relación icónica con los monumentos arquitectónicos patrimoniales de Quito nos señala un recorte de la historia, un vestigio de la herencia, la magnificencia de la arquitectura colonial, la riqueza ornamental de los detalles, la finura de los artistas, la destreza de los artesanos. La propuesta insinúa un brote recurrente del efecto en el entorno visual urbano, la existencia de una ciudad repetida en fragmentos que convive con el todo, como si se tratase de otra ciudad viviendo paralelamente con su origen. "De este modo, el viajero al llegar deparase con dos ciudades: Una perpendicular sobre el lago y la otra reflejada de cabeza para abajo" (Calvino, 1990, p.53).

La tercera y última fisura que expondremos reside en la volubilidad de las sombras. Sabemos que la luz es la substancia primordial de la fotografía pero, curiosamente, resulta que ahora nuestro centro de interés (la sombra) carece de luz. Podríamos decir que es precisamente su antagónico y por esa misma razón el sentido cambia radicalmente. En la mayoría de los casos fotografiamos objetos que reflejan luz, hacemos una medición de esa luz reflejada y ajustamos la cámara a la temperatura de la luz incidente que opera sobre el objeto. Mas, nada de eso se aplica a la sombra, porque en teoría no hay medida para la oscuridad. Las sombras proyectadas siempre del lado opuesto a la fuente luminosa aparecen en la foto como siendo líneas y planos dibujadas sobre las piedras, maderas y paredes de los pisos y fachadas. Lo que sorprende de esas sombras, es que si bien representan el objeto que las origina, no siempre son la figura fiel de ese objeto, porque ellas se modifican en perfecta conjunción con las formas irregulares de la superficie en donde se proyectan. O sea, el propio "objeto ausente" es percibido únicamente a través de su sombra, solo que cadenciosamente desfigurado. 


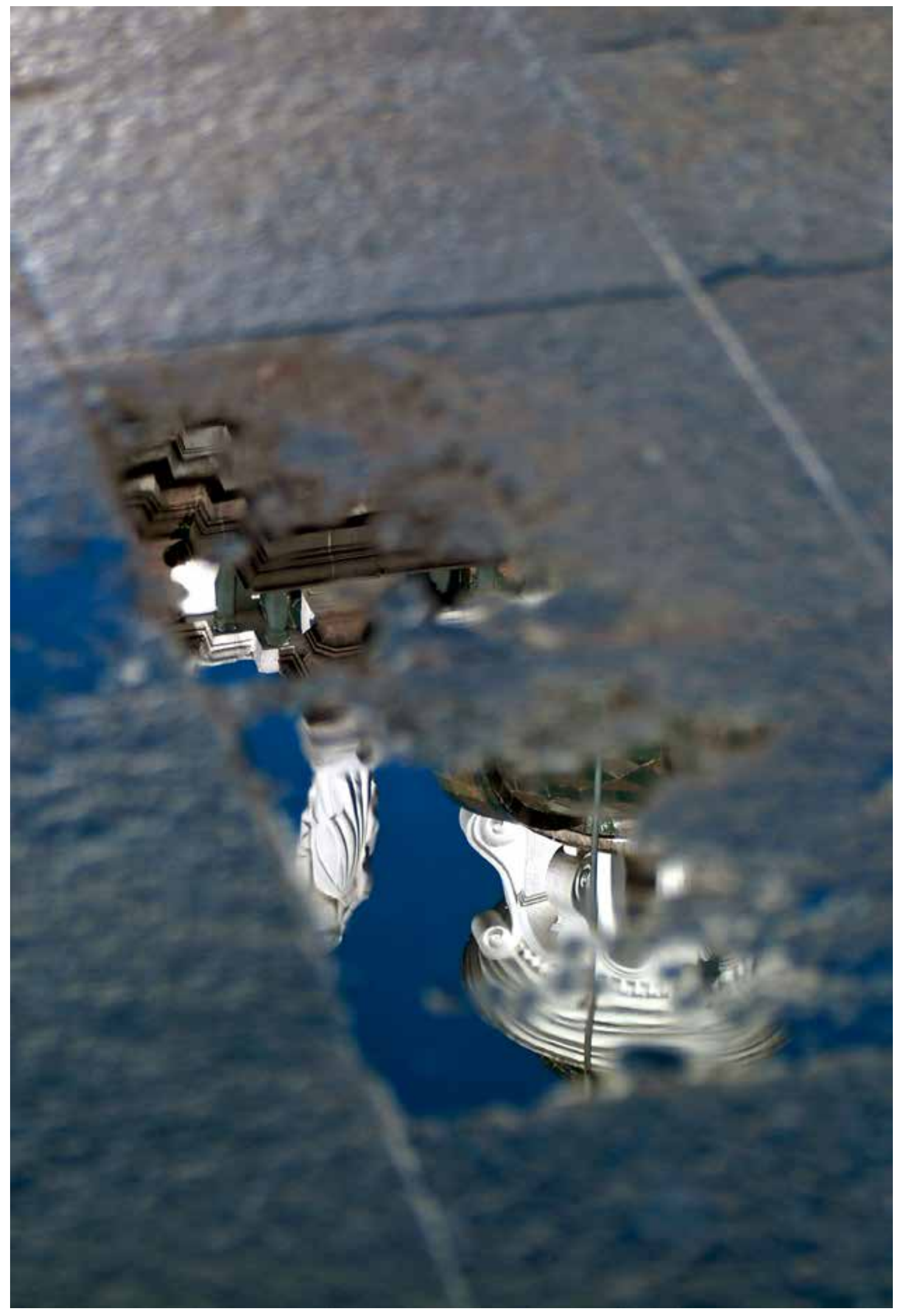

Figura 3. Raúl Yépez Collantes [YEPO]. Quito, mayo de 1999. De la serie El otro paisaje. Fuente: www.yepo-photo.com 


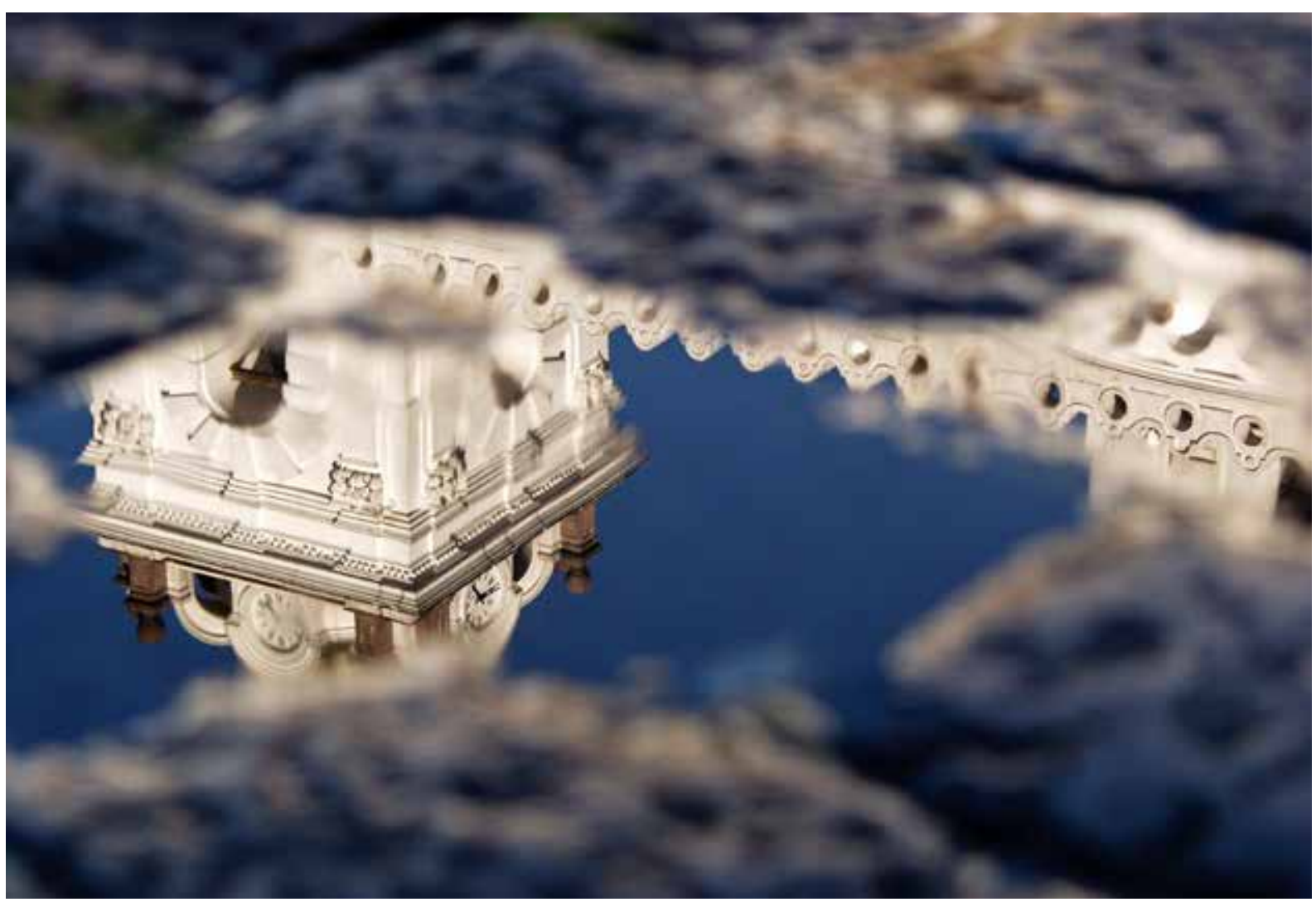

Figura 4. Raúl Yépez Collantes [YEPO]. Quito, mayo de 1999.

De la serie El otro paisaje. Fuente: www.yepo-photo.com

Puede verse en esta fotografía la gran puerta de madera de roble de 4 metros de altura, que da acceso a la Capilla de Cantuña, recinto de oración que forma parte del monumental complejo arquitectónico de San Francisco, en el Centro Histórico de Quito. Debido a la posición rasante de la luz solar, muy temprano en la mañana, se produce un efecto de sombras alargadas y organizadas bajo una doble perspectiva: una originada por sus propias proyecciones y, la otra, causada por el ángulo de toma muy cerca de la puerta. Toda la composición es una perfecta geometría de líneas perspectivas que convergen en dos puntos de fuga, uno de ellos centrado en el extremo izquierdo de la foto y el otro, del lado opuesto. El encuadre en vertical, acentúa la verticalidad de la puerta, de la columnata del portal y de las sombras que se proyectan sobre ellas, dándoles presencia y jerarquía.

El ajuste intencional de las figuras sombreadas con los planos que las acogen transmite al espectador la idea de que la puerta, el muro y la grada, están decoradas de sombra. Esa interpretación, un tanto metafórica, reivindica las sombras, alejándolas del mundo de los abismos, del espectro y de la soledad. El deseo personal de dar vida a la sombra pretende discrepar con la sensación de sombrío, de lúgubre, mancha o defecto, y creer en la dosis de vitalidad que la fotografía siempre inyecta al motivo, aunque sea este, la muerte misma. Queremos, antes de nada, conceder a las sombras un papel estético, aprovechando con creatividad los efectos que ellas producen en convivencia con nuestro cotidiano urbano. Una forma de revivir la sombra, usando acepciones de vestigio, puede ser encontrada en un ensayo de Eduardo Viera da Cunha (2004) titulado "El negativo: sombras densas y claras de la melancolía”:

La sombra de alguna cosa designa metafóricamente su inverso. Un inverso que se adhiere, que se pega a la cosa de la cual se originó y que, inseparable y melancólicamente, la acompaña, la persigue: la asombra. La noche, la muerte, el negro, lo invisible son los inversos del día, de la vida, del blanco, de lo visible. Y son, al mismo tiempo, sus prolongamientos (p.160).

La última foto que veremos para ilustrar esta fisura fue hecha en el preciso lapso en que el sol del amanecer proyectaba las sombras de la reja que protege el interior del acceso al Convento de San Francisco. De este espacio de transición, habilitado para la circulación 
de los visitantes y con una angulación en contra picada se captó la toma. Se percibe la proyección de las sombras de la armazón de hierro en la superficie cóncava de uno de los arcos de la entrada y en el muro que lo sustenta. Una cornisa de piedra remata el muro, coincidiendo con el nacimiento del arco (Figura 6).

Aquel ornato, compuesto compositivamente en diagonal al plano, descompone la foto en dos segmentos irregulares bien definidos. Uno que proyecta unas sombras sin aparente organización y otro cuyas sombras se “incrustan" en la cornisa del muro de piedra. Esas líneas elípticas y alargadas, diseñadas por el sol en el dorso interior del arco, recuerdan, de algún modo, las armaduras modulares y articuladas de los antiguos guerreros. Sin constituirse en un estricto centro de interés, la zona de aquella coraza de sombras curvadas posiblemente sea la que más llama la atención. Ocupando un espacio discreto, se percibe debajo la silueta de la puerta de hierro superponiéndose al fondo azulado del cielo. Este detalle cromático intencional, que debemos al uso de la fotografía a color, busca incorporar en la composición un elemento de colores vívidos, actuando en contraste con los tonos oscuros característicos del efecto y del objeto fotografiado.

\section{Conclusiones:}

Ha de entenderse que luego de estas exploraciones visuales, el lector tenga la posibilidad de ligar algunas definiciones con los elementos fenomenológicos que se constituyen en fisuras en la percepción del entorno visual urbano. Está claro que el producto resultante se torna evidente a través de la fotografía y que, probablemente, la seducción que ella ejerce en la mayoría de nosotros se deba al hecho de que la fotografía produce esencialmente imágenes, esos códigos poderosos a los que estamos vinculados desde antes mismo del aparecimiento de la escritura.

Las imágenes han moldeado y construido nuestro pensamiento, han relatado nuestra historia, han acompañado nuestra evolución y dado sentido a nuestra existencia. Pero en este artículo, lo que interesa también es saber cómo la imagen fotográfica lidia con las interferencias en el campo del arte. Nuestros lectores, como en todos los casos de la apreciación artística, están divididos, a groso modo, entre los que tienen conocimiento académico o empírico sobre el arte de la fotografía y los que no. Tanto en unos como en otros, las imágenes son vistas de modos distintos, pero siempre están en "situación de mediación entre el espectador y la realidad" (Aumont, 1993, p.98). En ese proceso nos encontramos con una infinidad de posibilidades interpretativas.

Según Silva (2014) establecer un parangón sostenible entre el ciudadano y el artista consiste en que “mientras el arte público de hoy habla de 'intervenciones' o de 'performances', los ciudadanos, desde siempre, hacen la ciudad interviniéndola”(p. 231). Sin embargo, la presencia de fisuras perceptivas, tal cual las hemos planteado, no responde a este esquema. Quizá las palabras claves sean mostrar, hacer ver, aquello de lo cual ni el artista ha preparado ni el ciudadano ha intervenido. $\mathrm{Y}$ ahí es cuando la conjunción de los conceptos cobra relevancia. Llámese como sea, suerte de explorador, o alma de pionero, el caso es que, conforme lo he relatado, estos efectos de lo efímero se ofrecieron a la vista, de la forma más espontánea e inesperada. Por alguna razón, tienen gusto de un hallazgo imprescindible, un aparecimiento a descubrir, aunque siempre el ciudadano común haya convivido con ellos.

\section{Referencias}

Aumont, J. (1993). A Imagem. Campinas, Sao Paulo: Papirus.

Calvino, I. (1990) As cidades invisiveis. São Paulo: Companhia das Letras.

Cunha, E. (2004). O negativo: sombras densas e claras da melancolia. A fotografia nos processos artísticos contemporâneos. Alexandre Santos e Maria Ivone dos Santos. Org. Porto Alegre: Unidade Editorial da Secretaria Municipal da Cultura/ Editora da UFRGS.

Boyer, M. C. (1994). The City of Collective Memory. Its Historical Imagery and Architectural Entertainments. Cambridge Mass.: MIT Press.

Makowiecky, S. $A$ iconografia urbana e os espaços cênicos da memoria da cidade. Visualidades: Revista do Programa de Mestrado em Cultura Visual, Goiânia GO. 5(2), 32-63.

Meneses, UT. Bezerra De. Morfologia das cidades brasileiras. Introdução ao estudo da iconografia urbana. Revista USP. São Paulo (30): 144-155.

Montaner, J. (2002). Las formas del Siglo XX, Barcelona: Gustavo Gili.

Silva, A. (2014). Imaginarios, el asombro social, Quito: Editorial Quipus, Ciespal. 


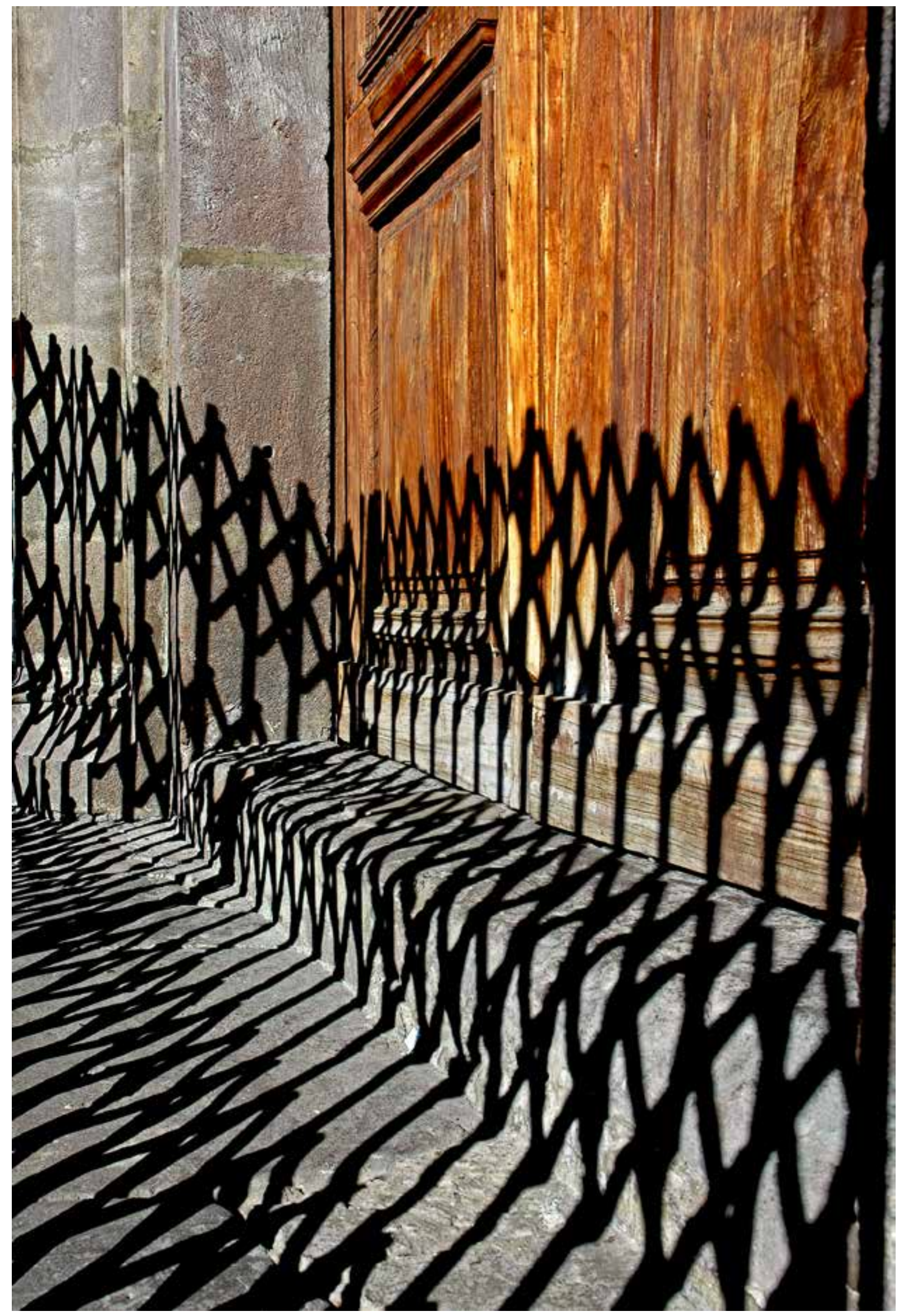

Figura 5. Raúl Yépez Collantes [YEPO]. Quito, mayo de 1999. De la serie El otro paisaje. Fuente: www.yepo-photo.com 


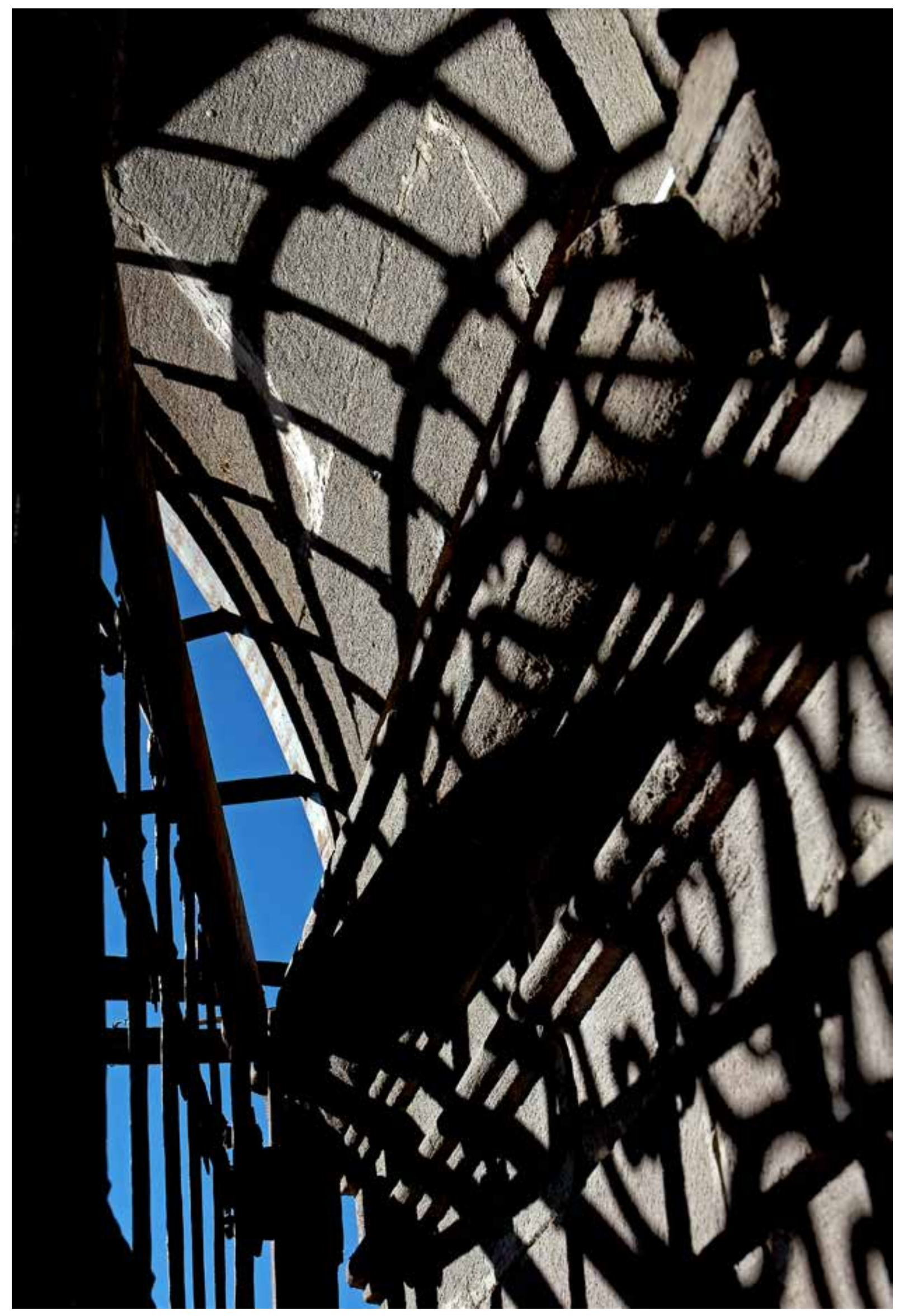

Figura 6. Raúl Yépez Collantes [YEPO]. Quito, mayo de 1999. De la serie El otro paisaje. Fuente: www.yepo-photo.com 